\title{
Validation of the shoal-biased pattern of bathymetric information on nautical charts
}

\author{
Christos Kastrisios ${ }^{\mathrm{a}}$ *, Brian Calder ${ }^{\mathrm{a}}$, Giuseppe Masetti ${ }^{\mathrm{a}}$, Peter Holmberg ${ }^{\mathrm{b}}$ \\ ${ }^{a}$ University of New Hampshire, Center for Coastal and Ocean Mapping/UNH-NOAA Joint Hydrographic Center, Durham, NH, \\ USA,Christos.Kastrisios@unh.edu,brc@ccom.unh.edu,gmasetti@ccom.unh.edu \\ ${ }^{b}$ National Oceanic and Atmospheric Administration, National Ocean Service, Office of Coast Survey, Hydrographic Survey \\ Division, Pacific Hydrographic Branch - Seattle, WA, USA, peter.holmberg@noaa.gov \\ * Corresponding author
}

Keywords: Nautical Chart Generalization, Chart Safety Constraint, Sounding Selection, Triangle Test

\begin{abstract}
:
The compilation of nautical charts comprises a number of tasks that are often monotonous, time consuming, and, as such, prone to human error. A long-term goal of the hydrographic community has thus been the automation of the process due to the unquestionable advantages of automation to the accuracy, reliability, and consistency of products for a reduced cost-to-productivity ratio. One of the tasks that has received the attention of automation efforts is the compilation of bathymetry on charts and more precisely the generation and generalization of depth curves and the selection and validation of charted soundings. There is, however, much room for improvement with current methods.
\end{abstract}

Charted soundings and depth curves complement each other in maintaining and emphasizing the morphological details and characteristic features of the seafloor on charts. They are derived from a more detailed dataset, either survey data or a larger scale chart, with generalization. Once the cartographer delineates the depth curves, he/she makes the selection of soundings to be charted following established cartographic practice rules (see, e.g., IHO 2017; NOAA 2018). Both tasks may be performed either fully manually, or partially manually through a computer-assisted method.

The goal is for the cartographer to retain the morphology and the characteristic features of the seabed and at the same time to honor the overarching principle that the expected depth (based on the charted bathymetric information) must not appear, at any location, deeper than the source information. According to S-4 (IHO, 2017), for well surveyed areas the "shoal-biased" pattern of charted soundings is achieved through the "triangular method of selection", where:

a) No actual sounding exists within a triangle of selected soundings which is less than the least of any of the soundings defining the edges of the triangle (hereinafter: triangle test); and

b) No source sounding exists between two adjacent selected soundings forming an edge of the triangle which is less than the lesser of the two selected soundings (hereinafter: edge test).

Motivated by the need for automated tools that perform consistently and satisfactorily in every geographic situation, and in the context of a developing project for a fully automated solution in nautical chart production, this paper presents our research work on the development of a comprehensive solution for the validation of the shoal-biased pattern of charted bathymetric information. This includes an algorithmic implementation of the triangle test that eliminates the false positives of previous implementation efforts near and within linear features (see Figure 1), as well as the first automated implementation of the edge test in the literature. For the above implementations we incorporate the available bathymetric information on the chart, e.g., coastlines (natural and man-made), depth curves, soundings, obstructions, and wrecks (see Kastrisios and Calder 2018; Kastrisios et al. 2019).

The presented work also illustrates the importance of the edge test in the validation of the charted bathymetric information as it can identify shoals that the triangle test may not identify (see Figure 2), thereby proving that the edge test must not be disregarded by cartographers in the validation process.

However, the two tests share the intrinsic limitation of missing discrepancies between the charted and source bathymetric information, even if they are significant (see Figure 3 ). Thus, a fully automated solution based on a verbatim interpretation of the two tests as written in S-4 does not seem feasible. Therefore, we propose a surface-based validation test that will account - at the appropriate charting resolution - for the configuration of the seabed that would be mentally reconstructed by the mariner from the charted bathymetric information. This is expected to lead to a more realistic representation of the submarine relief and its navigationally significant features on charts from the available source information (see Kastrisios et al. 2019). 


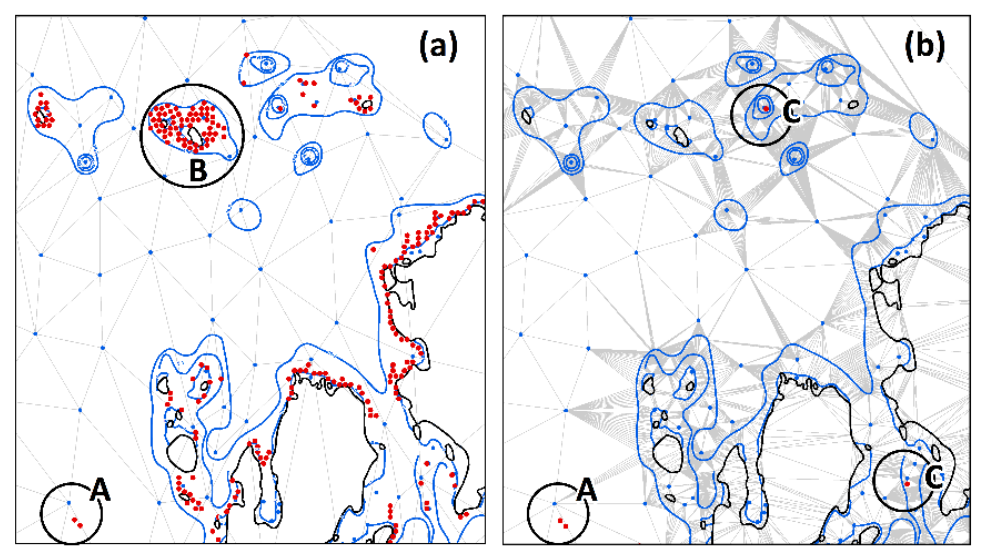

Figure 1. Our implementation of the triangle test (b) that incorporates all the available bathymetric information on charts flags only actual shoals (flags marked with "A" and "C") while eliminating the false positives (e.g., area marked with "B") from an implementation of the triangle test using only the selected soundings (a).

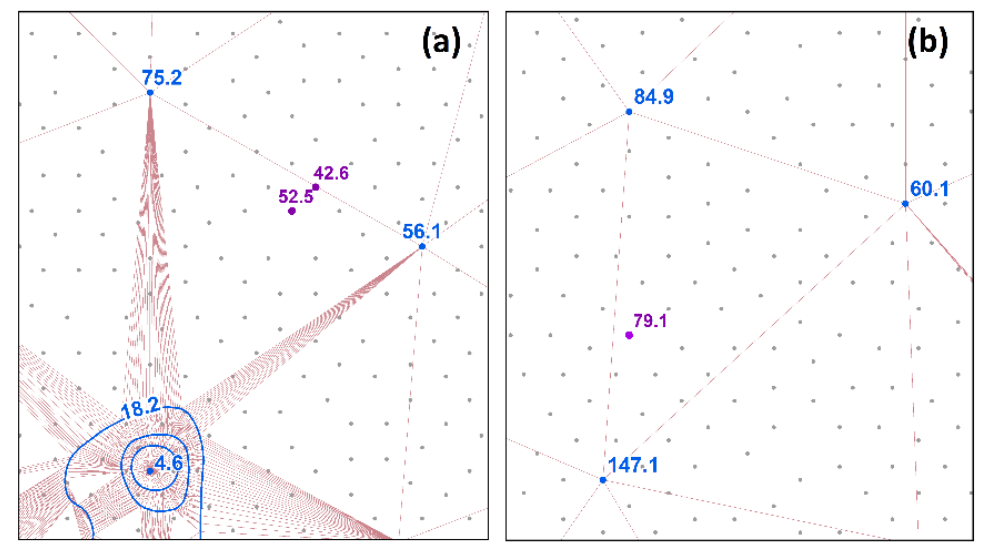

Figure 2. Shoals found only with the edge test proving its significance in the validation process.

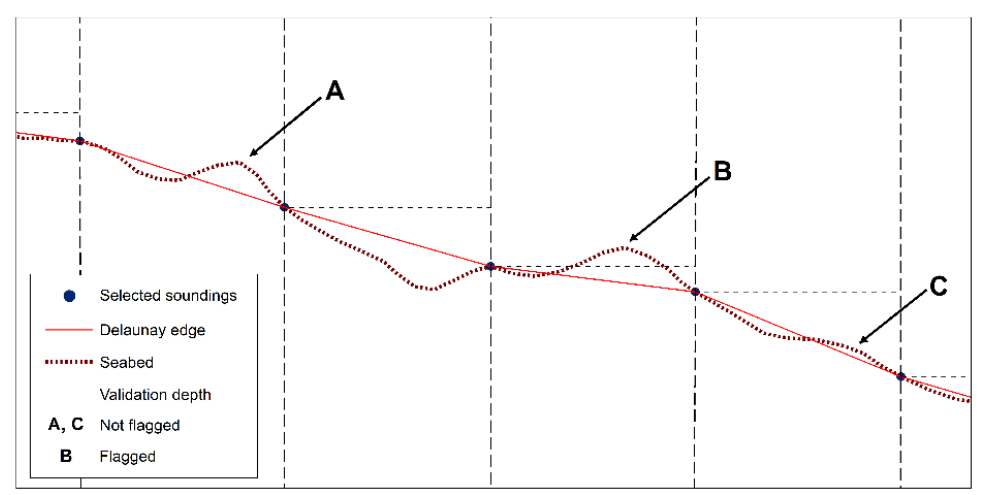

Figure 3. A profile view of the seabed, the selected soundings, and the Delaunay faces showing why the two tests fail to identify eminences that deviate significantly from the expected depth on chart, thus making a new, surface-based test indispensable.

\section{References}

IHO, 2017. International Hydrographic Organization. Regulations of the IHO for international (INT) Charts and Chart Specifications of the IHO. Publication S-4. Edition 4.7.0, July 2017, International Hydrographic Organization, Monaco. NOAA, 2018. National Oceanic and Atmospheric Administration. Nautical Chart Manual. Volume 1 - Policies and Procedures. Version 2018.2. Office of Coast Survey. 29 May 2018.

Kastrisios, C., and B.R. Calder. 2018. "Algorithmic implementation of the triangle test for the validation of charted soundings." Paper presented at the Proceedings of the $7^{\text {th }}$ International Conference on Cartography and GIS, Sozopol, Bulgaria, June 18-23.

Kastrisios, C., B.R. Calder, G. Masetti, and P. Holmberg. 2019. "Towards Automated Validation of Charted Soundings: Existing Tests and Limitations.” Geo-spatial Information Science. Taylor \& Francis (In Press) 